\title{
A method for obtaining flexible broccoli varieties for sustainable agriculture
}

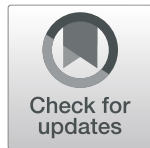

Simona Ciancaleoni and Valeria Negri

\begin{abstract}
Background: The use of high inputs in agriculture resulted in few varieties (hybrids and pure lines) used in all agricultural systems. Also varieties of vegetables, including broccoli, for organic and low-input agriculture, are almost exclusively hybrids, since there are very few specific breeding programs and varieties for sustainable agriculture systems.

A strategy to overcome this issue is the adoption of specific breeding programs for developing heterogeneous varieties (i.e. synthetics, open pollinated varieties, composite cross populations and mixtures). In fact, heterogeneous varieties are able to evolve and adapt to specific agro-climatic conditions.

The aim of this study was to develop a method (an Evolutionary Breeding Program, EBP) for obtaining heterogeneous varieties of broccoli and test its efficiency in developing highly diverse varieties, as needed in sustainable agriculture. A synthetic variety originated from a landrace was multiplied in different environments for 3 cycles and morphophenological and genetic diversity of the derived populations were assessed.

Results: The presented results are the first and unique indication about the efficiency of a short-time EBP for an allogamous species like broccoli.

Few morphological changes were observed among varieties multiplied in different environments with different agroclimatic conditions. This could be probably due to the initial genetic diversity of the landrace from which the populations were selected and also to the great plasticity of the crop. However, SSR data highlighted a genetic differentiation among populations multiplied for two/three years across Europe and in Central Italy, that was not so evident when considering morphological data only.

Conclusions: Few years of multiplication in different environments resulted in genetically differentiated broccoli populations that nonetheless preserved the original genetic diversity and productivity level and appear to evolve in relationship to different environments: the applied EBP is useful for developing heterogeneous materials for sustainable agriculture.
\end{abstract}

Keywords: Brassica oleracea L. var. italica, Evolutionary breeding program, Populations, Sustainable agriculture, Genetic diversity, Adaptation

\footnotetext{
* Correspondence: valeria.negri@unipg.it

Dipartimento di Scienze Agrarie, Alimentari e Ambientali (DSA3), Università

degli Studi di Perugia, Borgo XX Giugno 74, 06121 Perugia, Italy
}

(c) The Author(s). 2020 Open Access This article is licensed under a Creative Commons Attribution 4.0 International License, which permits use, sharing, adaptation, distribution and reproduction in any medium or format, as long as you give appropriate credit to the original author(s) and the source, provide a link to the Creative Commons licence, and indicate if changes were made. The images or other third party material in this article are included in the article's Creative Commons licence, unless indicated otherwise in a credit line to the material. If material is not included in the article's Creative Commons licence and your intended use is not permitted by statutory regulation or exceeds the permitted use, you will need to obtain permission directly from the copyright holder. To view a copy of this licence, visit http://creativecommons.org/licenses/by/4.0/. The Creative Commons Public Domain Dedication waiver (http://creativecommons.org/publicdomain/zero/1.0/) applies to the data made available in this article, unless otherwise stated in a credit line to the data. 


\section{Background}

Brassica oleracea L. $(2 \mathrm{n}=2 \mathrm{x}=18)$ is an economically important vegetable and its world annual commercial production (cauliflower and broccoli) is over $25 \mathrm{Mt}$, currently cultivated on about 1.4 Mha worldwide [1]. China is the first country in producing broccoli and cauliflower (10 million tons), meanwhile, in Italy, the estimated production of both vegetables is about 390,000 tons [1] of which $10 \%$ is obtained in organic agriculture [2]. Among the different $B$. oleracea subspecies, broccoli (B. oleracea L. var. italica Plenck, also identified as B. oleracea L. spp. capitata L. (DC.) convar. Botrytis (L.) Alef. var. italica Plenck [3]) is an important source of vitamins, minerals and antioxidants.

Currently, organic farmers largely depend on broccoli varieties bred for high external input in conventional farming systems $[4,5]$, and in particular, broccoli varieties are almost exclusively hybrids [5], due to lack of specific breeding programs and varieties for sustainable (organic and low-input) agriculture.

Suitable varieties for sustainable agriculture should have specific characteristics (as yield stability under different agro-climatic conditions, resistances to biotic and abiotic stresses, competition ability with weeds) in order to avoid the utilisation of external input like pesticides, herbicides and chemical fertilizers $[5,6]$. In the context of sustainable agriculture, to allow varieties to evolve and adapt to specific agro-climatic conditions is also important [7]. This is possible only when heterogeneous varieties (i.e. landraces, synthetics, open pollinated varieties, composite cross populations, mixtures) are used and reproduced on-farm for generations.

As a consequence, breeding programs specifically adopted for sustainable agriculture should consider all the above. Among many breeding approaches, the Evolutionary plant Breeding Program (EBP), combining natural and artificial selection in target environments, is suggested to be effective in obtaining heterogeneous varieties for organic and low-input agriculture [8-13].

The success of an EBP, like that of any other breeding program, is mainly due the genetic diversity of the initial materials. For example, EBP in cereals has been based on composite cross populations (CCP) or mixtures $[8,10,13,14]$ that can be originated from old varieties or landraces. Also for allogamous species, genetically variable varieties, like open pollinated, synthetic varieties or landraces, which have advantages in terms of yield stability and resistance [15], have been recommended. In particular, landraces could be the best starting materials for developing varieties suitable for organic and low-input agriculture $[5,16]$ due their great genetic diversity that provides a buffer against environment fluctuations and adaptation to specific environments across time.
An assessment of genetic diversity is therefore essential for the organization, development and control of a breeding program. The genetic diversity and structure of populations under selection can be efficiently evaluated by molecular markers. Depending on their type (i.e. neutral or related-to-gene markers) they can also provide information about the intensity of both natural and human selection and about the genetic divergence of populations developed across years and environments. To this purpose, different types of molecular markers have been used. For example, genetic changes in maize composite populations under Reciprocal Recurrent Selection (RRS) were analyzed by using Restriction Fragment Length Polymorphism (RFLP) [17, 18], Simple Sequence Repeats (SSR) [19-21] and Single Nucleotide Polymorphism (SNP) [22]. SSR were also used to evaluate the genetic changes in different maize populations obtained after about 20 years of stratified mass selection on two historical Portuguese populations [23]. Considering autogamous species, the genetic evolution over time and space of wheat CCP was assessed by RFLP [24, 25] and by SSR [26] and that of a barley CCP by using SSR [13].

Agronomic performances of different broccoli heterogeneous varieties or other broccoli breeding materials for sustainable agriculture have been already reported [5, 27-29], but few data are available on genetic diversity of broccoli breeding materials [30-32] and on their evolution and adaptations under different agro-climatic conditions.

Considering this lack of knowledge, the aims of this paper were to i) describe a EBP method for developing flexible broccoli varieties (i.e. populations, for sustainable agriculture), ii) assess the adaptation potential and the morpho-phenological and genetic changes of the populations developed with this method in different environments and iii) in the adaptation area across years.

\section{Results \\ Comparisons of populations multiplied for up to two cycles in different environments \\ Morpho-phenological characterisation and differentiation}

The ANOVA analysis showed that the entries differ for all of the morpho-phenological traits recorded with great differences generally observed between the populations and three of the hybrids ( $\mathrm{HH}, \mathrm{HHH}, \mathrm{HHHH}$ ) (Table 1). For the traits weight of the main head $(Y L D)$ and number of secondary heads $(H N)$ the populations derived from the initial synthetic by multiplication for two years were not different from each other. In particular, YLD values ranged from $11.05 \mathrm{~g}$ (Syn2-TER) to $324.58 \mathrm{~g}$ $(\mathrm{HHH})$, as populations formed a little main head and many (up to 36) secondary heads while most of the hybrids did not form any secondary heads $\mathrm{HHH}$, among 
Table 1 Average values and standard deviations of morpho-phenological trait for the entries (two years of multiplication)

\begin{tabular}{|c|c|c|c|c|c|c|c|c|c|c|c|c|}
\hline & $\mathrm{DH}$ & $D M$ & $H N$ & $Y L D$ & $M-Y L D$ & $T-Y L D$ & $\mathrm{HeH}$ & $\mathrm{HeW}$ & $S W$ & $P H$ & $P D$ & V \\
\hline $\mathrm{LR}$ & $203 a$ & $215 b$ & $34.00 a$ & $26.73 c$ & $6.47 \mathrm{bcd}$ & $242.04 b c$ & $8.50 a$ & $3.50 \mathrm{~cd}$ & $1.26 \mathrm{bcd}$ & $50.78 a$ & $66.78 b$ & $6.47 a b$ \\
\hline SD & \pm 4.83 & \pm 2.21 & \pm 10.95 & \pm 11.91 & \pm 1.93 & \pm 84.08 & \pm 1.56 & \pm 1.06 & \pm 0.37 & \pm 10.14 & \pm 14.58 & \pm 1.50 \\
\hline Syn1-PG & $204 a$ & $215 b$ & $33.00 \mathrm{a}$ & $28.39 c$ & $6.10 \mathrm{~cd}$ & $228.65 \mathrm{~cd}$ & $8.71 a$ & $3.72 \mathrm{~cd}$ & $1.29 \mathrm{bcd}$ & $50.63 a$ & $62.17 b c$ & $6.48 a b$ \\
\hline SD & \pm 4.63 & \pm 3.31 & \pm 8.23 & \pm 11.43 & \pm 1.69 & \pm 71.16 & \pm 1.71 & \pm 1.36 & \pm 0.39 & \pm 7.27 & \pm 6.30 & \pm 1.25 \\
\hline Syn2-PG & $191 c$ & $207 d$ & $33.00 a$ & $38.97 \mathrm{c}$ & $5.36 \mathrm{~d}$ & $213.74 c d$ & $9.11 a$ & $4.35 \mathrm{~cd}$ & $1.33 \mathrm{bcd}$ & 44.83ab & $80.39 a$ & $6.83 a b$ \\
\hline SD & \pm 2.29 & \pm 0.21 & \pm 8.57 & \pm 34.79 & \pm 1.80 & \pm 70.67 & \pm 3.07 & \pm 2.39 & \pm 0.44 & \pm 9.73 & \pm 10.46 & $1.59 \pm$ \\
\hline Syn2-GR & $197 b$ & $219 a$ & $36.00 a$ & $22.09 c$ & $3.32 \mathrm{e}$ & 144.49de & $5.97 b$ & $5.34 \mathrm{c}$ & $1.36 \mathrm{bcd}$ & $48.63 a$ & $63.38 b c$ & $7.04 a$ \\
\hline SD & \pm 0.00 & \pm 2.72 & \pm 8.45 & \pm 11.30 & \pm 0.89 & \pm 59.16 & \pm 1.81 & \pm 1.06 & \pm 1.23 & \pm 6.76 & \pm 11.69 & \pm 1.49 \\
\hline Syn2-TER & $188 \mathrm{c}$ & 207d & $35.00 \mathrm{a}$ & $11.05 c$ & $1.93 e$ & $81.05 e$ & $6.41 b$ & $5.15 \mathrm{~cd}$ & $0.94 d$ & $39.35 b$ & $48.90 d$ & $4.00 c$ \\
\hline SD & \pm 2.55 & \pm 1.79 & \pm 11.13 & \pm 4.55 & \pm 0.67 & \pm 37.27 & \pm 1.13 & \pm 1.18 & \pm 0.20 & \pm 10.23 & \pm 12.84 & \pm 1.52 \\
\hline Syn2-FR & $204 a$ & $216 b$ & $29.00 a$ & $44.46 c$ & $7.97 a$ & 266.72abc & $8.81 a$ & $3.89 \mathrm{~cd}$ & $1.53 b$ & $48.97 a$ & $66.48 \mathrm{~b}$ & $6.55 a b$ \\
\hline SD & \pm 4.94 & \pm 1.90 & \pm 9.15 & \pm 91.06 & \pm 2.96 & \pm 139.01 & \pm 3.01 & \pm 2.94 & \pm 0.53 & \pm 8.55 & \pm 11.67 & \pm 1.52 \\
\hline Syn2-UK & $203 a$ & $215 b$ & $31.00 \mathrm{a}$ & $23.41 c$ & $6.87 a b c$ & $233.56 c$ & $8.70 a$ & $3.29 d$ & $1.08 \mathrm{~cd}$ & 45.63ab & $64.38 \mathrm{bc}$ & $5.72 b$ \\
\hline SD & \pm 450 & \pm 1.85 & \pm 10.61 & \pm 8.67 & \pm 1.88 & \pm 83.01 & \pm 1.54 & \pm 1.06 & \pm 0.30 & \pm 9.86 & \pm 8.17 & \pm 1.40 \\
\hline $\mathrm{H}$ & $192 c$ & $212 b$ & $29.00 a$ & $30.42 c$ & 7.57ab & $252.04 a b c$ & $9.59 a$ & $5.04 \mathrm{~cd}$ & $1.46 \mathrm{bc}$ & $44.81 \mathrm{ab}$ & $36.31 \mathrm{e}$ & $2.94 \mathrm{C}$ \\
\hline SD & \pm 0.00 & \pm 3.18 & \pm 9.50 & \pm 9.07 & \pm 2.26 & \pm 119.79 & \pm 2.14 & \pm 1.24 & \pm 0.24 & \pm 9.53 & \pm 9.54 & \pm 0.51 \\
\hline $\mathrm{HH}$ & $101 e$ & $134 f$ & $0.00 \mathrm{~b}$ & $312.62 \mathrm{a}$ & $0.00 f$ & $312.62 a b$ & $9.58 a$ & $14.53 a$ & $3.45 \mathrm{a}$ & $29.28 c$ & $57.69 \mathrm{~cd}$ & - \\
\hline SD & \pm 1.83 & \pm 3.55 & \pm 0.00 & \pm 104.09 & \pm 0.00 & \pm 104.09 & \pm 2.17 & \pm 3.11 & \pm 0.44 & \pm 5.31 & \pm 7.12 & - \\
\hline $\mathrm{HHH}$ & $107 d$ & $137 e$ & $0.00 \mathrm{~b}$ & $324.58 \mathrm{a}$ & $0.00 f$ & $324.58 \mathrm{a}$ & $9.64 a$ & $14.15 \mathrm{a}$ & $3.61 a$ & $28.60 \mathrm{~cd}$ & $64.52 \mathrm{bc}$ & - \\
\hline SD & \pm 8.64 & \pm 5.32 & \pm 0.00 & \pm 120.88 & \pm 0.00 & \pm 120.88 & \pm 2.41 & \pm 4.10 & \pm 0.39 & \pm 4.20 & \pm 7.15 & - \\
\hline $\mathrm{HHHH}$ & $107 d$ & $140 \mathrm{e}$ & $0.00 \mathrm{~b}$ & $224.68 b$ & $0.00 f$ & $229.82 \mathrm{~cd}$ & 7.82ab & $11.37 b$ & $3.69 a$ & $22.05 d$ & 71.33ab & - \\
\hline SD & \pm 5.54 & \pm 6.77 & \pm 0.00 & \pm 105.55 & \pm 0.00 & \pm 105.41 & \pm 1.70 & \pm 2.86 & \pm 0.81 & \pm 5.83 & \pm 11.76 & - \\
\hline
\end{tabular}

B. oleracea var. italica original LR, Syn1-PG, its derived populations by two years of multiplication across Europe and hybrid controls Averages followed by the same letters are not significantly different at $P<0.05$ (Tukey HSD)

the hybrids, and Syn2-FR, among the populations, showed the highest total yield (324.8 and $266.2 \mathrm{~g}$, respectively).

Considering the inflorescence emission and maturation date $(D H$ range $=101-204 \mathrm{dd} ; D M$ range $=134-$ $219 \mathrm{dd}$ ), generally, the latest were the populations, the earliest the hybrids, with the exception of H. LR, Syn1PG, Syn2-FR, Syn2-UK and Syn2-GR were the latest for inflorescence emission date, with Syn2-GR also late in maturation. Regarding traits related to head characteristics, generally, hybrids showed higher values than populations: $\mathrm{HeH}$ range $=6.41-9.59 \mathrm{~cm}$, $(\mathrm{Syn} 2-\mathrm{TER}$ and $\mathrm{H}$, respectively), $\mathrm{HeW}$ range $=3.29-14.53 \mathrm{~cm}$ (Syn2-UK and $\mathrm{HH}$, respectively) and $S W$ range $=0.94-3.69 \mathrm{~cm}$ (Syn2TER and $\mathrm{HHHH}$, respectively). The hybrids showed the lowest plant height, while LR and Syn1-PG the highest $(P H$ range $=22.05-50.78 \mathrm{~cm}, \mathrm{HHHH}$ and $\mathrm{LR}$, respectively). Regarding plant diameter $(P D$ range $=36.31-$ $80.39 \mathrm{~cm}$, in $\mathrm{H}$ and Syn2-PG, respectively), all the entries showed similar values, with the exception of $\mathrm{H}, \mathrm{HH}$ and Syn2-TER showing the lowest values. No differences were found among populations regarding vigour with the only exception of Syn2-TER (4.0) which was the less vigorous one.

The first two PCA axes accounted for $83.57 \%$ of total data variability, with the addition of the third axis the $97.06 \%$ of the total variability was explained (Fig. 1). The entries were clustered in two groups: the first one included $\mathrm{HH}, \mathrm{HHH}$ and $\mathrm{HHHH}$, while the second included the populations with Syn2-TER and $\mathrm{H}$ as subgroups of this cluster. Most of the morphophenological traits had large effects on the ordination of entries (as indicated by the lengths of their vectors along the first two Axis).

The variables were clustered into four groups: the first one included $Y L D, S W$ and $H e W$, the second one included $T-Y L D$ and $H e H$, the third one $P D$ and $V$, while the last group included all the other variables. Within each group, variables were highly positively correlated, but the variables of the first group were negatively correlated to those belonging to the third group. The variables of the second group were not correlated with those included in the third group, while they were positively correlated with those belonging to the first group (Fig. 1). 


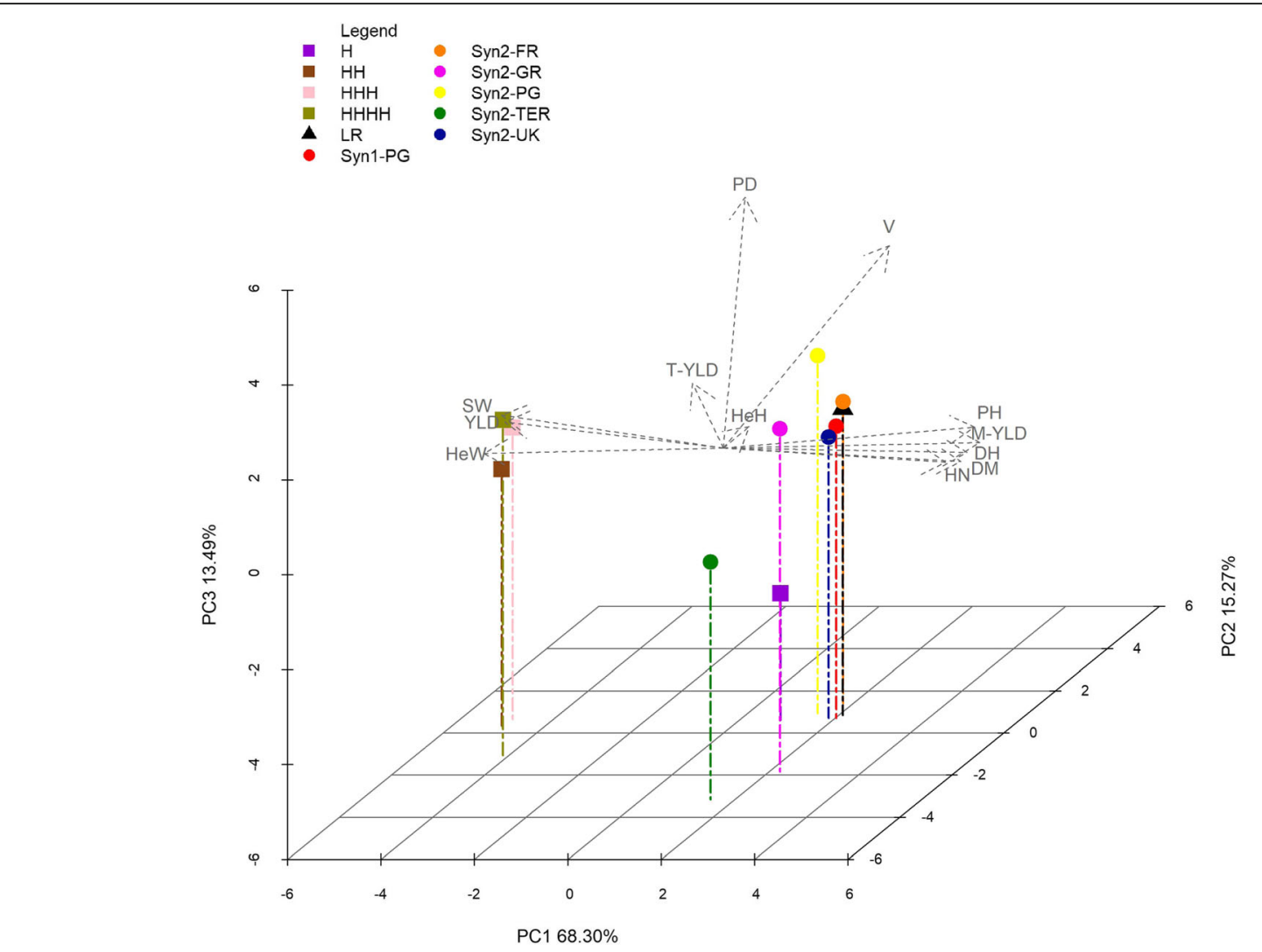

Fig. 1 PCA based on morpho-phenological traits recorded for each entry (two years of multiplications). B. oleracea var. italica original LR, Syn1-PG, its derived populations by two years of multiplication across Europe and hybrid controls. Coloured symbols represent the different entries analysed as from the legend, grey dotted arrow represent the morpho-phenological traits coded as from Table 4

\section{Genetic characterisation and differentiation}

Averages and standard errors relative to the main genetic parameters calculated by entry over the 22 SSR loci are reported in Table 2.

All the entries were characterised by similar number of alleles $(\mathrm{N})$. In general, $\mathrm{Na}$ was higher than $\mathrm{Ne}$ in all the entries. In populations, $\mathrm{Na}$ ranged from 2.45 ( \pm 0.205 , Syn2-TER) to $3.50( \pm 0.327, \mathrm{LR})$ and $N e$ ranged from $1.78( \pm 0.126$, Syn2-FR) to $2.38( \pm 0.188$, Syn1-PG), hybrids generally had lower values of $\mathrm{Na}$ and $\mathrm{Ne}$ than the populations.

Populations did not differ for $\mathrm{Ho}$ and $\mathrm{He}$, while obviously differed from hybrids.

Fixation index $(F)$ values were close to 0 for all the populations. The existence of negative values in some populations and in all the hybrids hinted to a heterozygosity excess.

Finally, all Fst values obtained from pairwise comparisons were highly significant $(P<0.01)$, with the only exception of the comparison between LR and Syn1-PG (Table 3). Considering two years of multiplication, significant pairwise Fst comparisons between the LR and derived populations increased from 0.026 to 0.066 . In addition, a crescendo of differentiation was found between Syn1-PG and populations derived by multiplication in other environments (from 0.039 between Syn1PG and Syn2-GR, to 0.070 between Syn1-PG and Syn2TER).

Similarly, a crescendo of differentiation was found between Syn2-PG and the same generation of multiplication in different environments (from 0.046 between Syn2-PG and Syn2-GR to 0.103 between Syn2-PG and Syn2-TER). The highest differentiation value was found between Syn2-FR and Syn2-TER, populations which were multiplied in very contrasting environments. As expected, the genetic differentiation between hybrids and between populations and hybrids was very high.

AMOVA (not shown) worked out on the total data showed that among- and within- population diversity accounted for 33 and $67 \%$ of total genetic variation, respectively. However, when it was worked out only considering the LR and its derived populations, the proportions were 11 and $82 \%$, respectively.

NJ tree results showed the presence of two main clusters (Additional file 4: Figure S3). A cluster included most of the individuals belonging to populations while 
Table 2 Averages and standard errors relative to the main genetic parameters calculated by entry (two years of multiplication)

\begin{tabular}{|c|c|c|c|c|c|c|c|}
\hline Entry & & $N$ & $\mathrm{Na}$ & $\mathrm{Ne}$ & Ho & $\mathrm{He}$ & $F$ \\
\hline \multirow[t]{2}{*}{ LR } & Mean & $30.91 d$ & $3.50 a$ & $2.37 a$ & $0.48 a$ & $0.51 a$ & $0.04 a$ \\
\hline & SE & 0.262 & 0.327 & 0.212 & 0.044 & 0.039 & 0.054 \\
\hline \multirow[t]{2}{*}{ Syn1-PG } & Mean & $31.32 \mathrm{~cd}$ & $3.50 a$ & $2.38 \mathrm{a}$ & $0.46 a b$ & $0.52 \mathrm{a}$ & $0.09 a$ \\
\hline & SE & 0.179 & 0.307 & 0.188 & 0.041 & 0.037 & 0.055 \\
\hline \multirow[t]{2}{*}{ Syn2-PG } & Mean & $31.36 \mathrm{bcd}$ & $2.95 a b$ & $2.18 a b$ & $0.53 a$ & $0.49 a$ & $-0.05 a$ \\
\hline & SE & 0.124 & 0.223 & 0.154 & 0.045 & 0.034 & 0.068 \\
\hline \multirow[t]{2}{*}{ Syn2-GR } & Mean & $31.86 a b c$ & $2.68 b$ & $1.93 a b$ & $0.39 a b c$ & $0.43 a$ & $0.05 a$ \\
\hline & SE & 0.100 & 0.202 & 0.143 & 0.037 & 0.037 & 0.052 \\
\hline \multirow[t]{2}{*}{ Syn2-TER } & Mean & $31.77 a b c$ & $2.45 b c$ & $1.86 \mathrm{bc}$ & $0.43 a b c$ & $0.42 \mathrm{a}$ & $-0.03 a$ \\
\hline & SE & 0.113 & 0.205 & 0.088 & 0.048 & 0.041 & 0.052 \\
\hline \multirow[t]{2}{*}{ Syn2-UK } & Mean & $31.95 \mathrm{ab}$ & $2.59 b$ & $2.03 a b$ & $0.46 a b$ & $0.45 a$ & $-0.03 a$ \\
\hline & SE & 0.045 & 0.204 & 0.138 & 0.048 & 0.042 & 0.057 \\
\hline \multirow[t]{2}{*}{ Syn2-FR } & Mean & $31.00 \mathrm{~d}$ & $3.00 \mathrm{~b}$ & $1.78 \mathrm{bcd}$ & $0.42 \mathrm{abc}$ & $0.38 a b$ & $0.07 a$ \\
\hline & SE & 0.208 & 0.255 & 0.126 & 0.057 & 0.041 & 0.079 \\
\hline \multirow[t]{2}{*}{$\mathrm{H}$} & Mean & $32.00 \mathrm{a}$ & $1.50 \mathrm{~d}$ & 1.34de & $0.22 b c$ & $0.18 c$ & $-0.17 a b$ \\
\hline & SE & 0.000 & 0.127 & 0.094 & 0.068 & 0.048 & 0.113 \\
\hline \multirow[t]{2}{*}{$\mathrm{HH}$} & Mean & $32.00 \mathrm{a}$ & $1.41 \mathrm{~d}$ & 1.41cde & $0.41 a b c$ & $0.21 \mathrm{C}$ & $-1.00 c$ \\
\hline & SE & 0.000 & 0.107 & 0.107 & 0.107 & 0.052 & 0.000 \\
\hline \multirow[t]{2}{*}{$\mathrm{HHH}$} & Mean & $32.00 \mathrm{a}$ & $1.27 \mathrm{~d}$ & $1.19 \mathrm{e}$ & $0.19 c$ & $0.10 c$ & $-0.51 b$ \\
\hline & SE & 0.000 & 0.097 & 0.084 & 0.084 & 0.042 & 0.177 \\
\hline \multirow[t]{2}{*}{$\mathrm{HHHH}$} & Mean & $31.91 \mathrm{abc}$ & $1.82 \mathrm{~cd}$ & $1.43 \mathrm{cde}$ & $0.34 a b c$ & $0.24 b c$ & $-0.21 a b$ \\
\hline & SE & 0.063 & 0.156 & 0.090 & 0.077 & 0.047 & 0.127 \\
\hline
\end{tabular}

Mean and standard errors relative to the number of successfully analysed genotypes $(\mathrm{N})$, observed $(\mathrm{Na})$, and effective alleles ( $\mathrm{Ne}$ ), observed heterozygosity (Ho), expected heterozygosity $(\mathrm{He})$ and Fixation Index $(F)$ worked out for original LR, Syn1-PG, its derived populations by two years of multiplication across Europe and hybrid controls on the basis of data recorded overall for the 22 markers used

Table 3 Fst values calculated for each pairwise comparison between original LR, Syn1-PG, its derived populations by two and three years of multiplication across Europe and in Central Italy, respectively, and hybrid controls

\begin{tabular}{|c|c|c|c|c|c|c|c|c|c|c|c|c|c|c|}
\hline & $L R$ & Syn1-PG & Syn2-PG & Syn3-PG & Syn2-GR & Syn3-GR & Syn2-TER & Syn3-TER & Syn2-UK & Syn2-FR & $\mathrm{H}$ & $\mathrm{HH}$ & $\mathrm{HHH}$ & $\mathrm{HHHH}$ \\
\hline LR & - & n.s. & & & & & & & & & & & & \\
\hline Syn1-PG & 0.000 & - & & & & & & & & & & & & \\
\hline Syn2-PG & 0.022 & 0.022 & - & & & & & & & & & & & \\
\hline Syn3-PG & 0.041 & 0.044 & 0.029 & - & & & & & & & & & & \\
\hline Syn2-GR & 0.042 & 0.039 & 0.046 & 0.066 & - & & & & & & & & & \\
\hline Syn3-GR & 0.093 & 0.086 & 0.131 & 0.132 & 0.107 & - & & & & & & & & \\
\hline Syn2-TER & 0.066 & 0.070 & 0.103 & 0.124 & 0.096 & 0.104 & - & & & & & & & \\
\hline Syn3-TER & 0.100 & 0.099 & 0.108 & 0.120 & 0.124 & 0.115 & 0.159 & - & & & & & & \\
\hline Syn2-UK & 0.057 & 0.050 & 0.073 & - & 0.076 & - & 0.104 & - & - & & & & & \\
\hline Syn2-FR & 0.056 & 0.064 & 0.082 & - & 0.101 & - & 0.108 & - & 0.116 & - & & & & \\
\hline $\mathrm{H}$ & 0.247 & 0.258 & 0.268 & 0.317 & 0.276 & 0.314 & 0.339 & 0.313 & 0.348 & 0.281 & - & & & \\
\hline $\mathrm{HH}$ & 0.221 & 0.221 & 0.239 & 0.282 & 0.246 & 0.305 & 0.308 & 0.285 & 0.278 & 0.268 & 0.461 & - & & \\
\hline $\mathrm{HHH}$ & 0.281 & 0.288 & 0.299 & 0.329 & 0.350 & 0.390 & 0.388 & 0.356 & 0.360 & 0.317 & 0.543 & 0.259 & - & \\
\hline $\mathrm{HHHH}$ & 0.213 & 0.215 & 0.224 & 0.251 & 0.265 & 0.304 & 0.295 & 0.288 & 0.278 & 0.262 & 0.425 & 0.175 & 0.162 & - \\
\hline
\end{tabular}

All comparison are significant $P<0.002$, only LR vs Syn1-PG Fst is not significant $P>0.05$ n.s not significant 
the other one to the hybrids. The first cluster showed others, although not completely differentiated, subclusters: Syn2-TER, Syn2-FR and Syn2-UK genotypes mostly clustered together. The within-population genetic variation was evident in populations, while hybrids generally showed a high genetic uniformity in accordance with their genetic structure.

The first three components of the PCoA accounted for $85.90 \%$ of genetic variation (Fig. 2). PCo1 (52.94\%) clearly separated populations from hybrids, while PCo2 (26.47\%) separated the hybrid $\mathrm{H}$ from the other entries. PCo3 (6.49\%) mainly discriminated Syn2-FR and Syn2TER from Syn2-UK and Syn2-GR.

\section{Comparison of populations multiplied for up to three cycles in Central Italy Morpho-phenological and genetic characterisation}

The ANOVA analysis showed that the assessed entries differ for many of the morpho-phenological traits recorded (Additional file 5: Table S2). All populations were clearly discriminated from $\mathrm{HH}, \mathrm{HHH}$ and $\mathrm{HHHH}$.
However, populations multiplied at the same site, with very few exceptions, did not show much differences and, generally, all populations obtained after three cycles of multiplication showed similar values to those found in the populations obtained after two cycles of multiplication. Worth of note is only that Syn2-GR was different from Syn3-GR and Syn2-TER from Syn3-TER for $\mathrm{HeH}$, Syn2-PG was different from the LR and the other populations multiplied in Perugia for $D H, D M$ and $P D$ and, finally, Syn3-PG was different from LR, Syn1-PG and Syn2-PG for $V$.

The PCA (with the first three axes accounting for $96.54 \%$ of total data variation) and the biplot showed that the three hybrids and hybrid $\mathrm{H}$ with populations clustered separately and that the variable clustering and relationship were similar to what previous observed (i.e. considering the morpho-phenological comparisons of populations multiplied for up two cycles in different environments, Additional file 6: Figure S4).

Averages and standard errors relative to the main genetic parameters calculated by entry over the 22 SSR loci

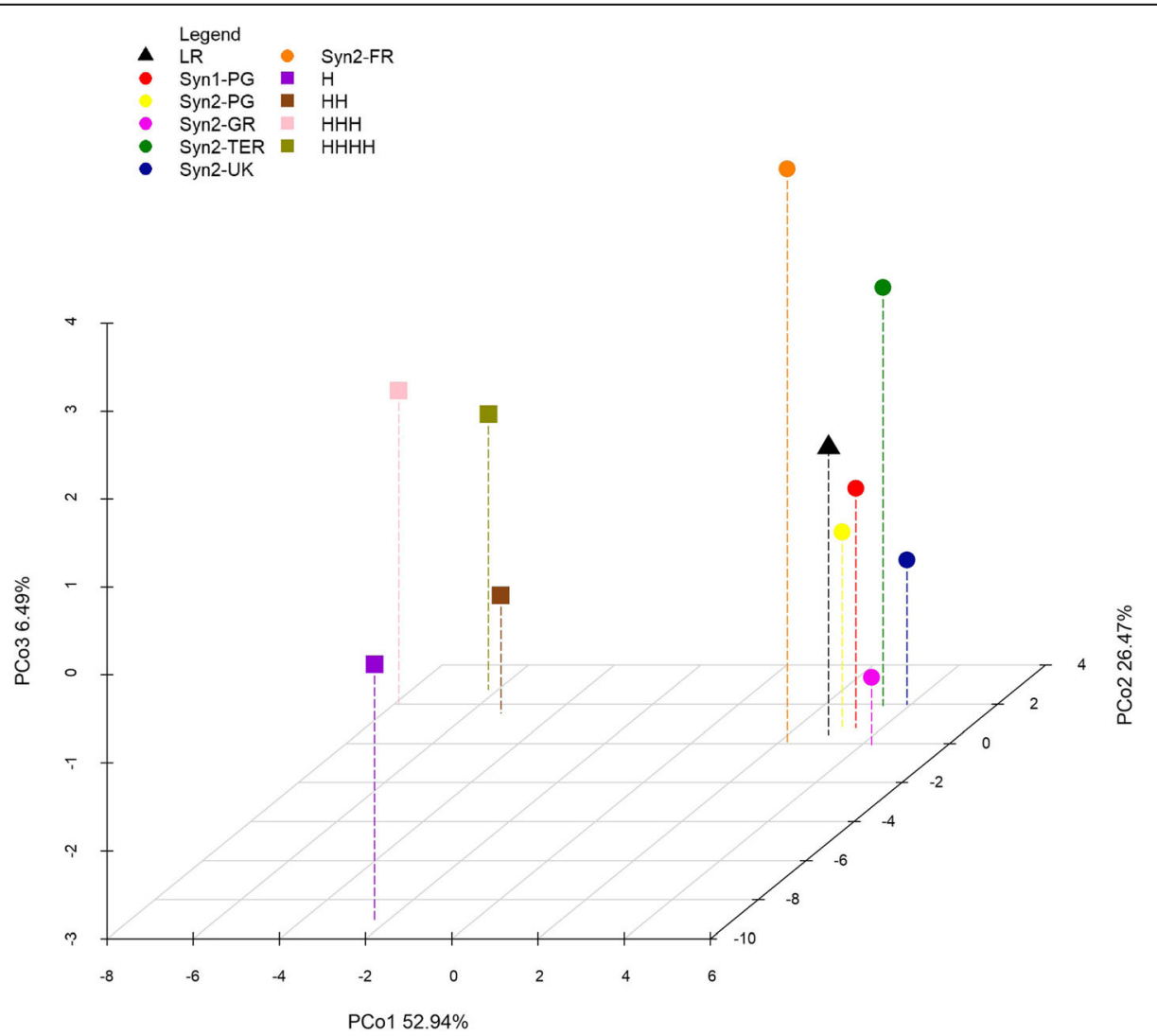

Fig. 2 PCoA based on average genetic distance of entries (two years of multiplication). B. oleracea var. italica original LR, Syn1-PG, its derived populations by two years of multiplication across Europe and hybrid controls. Coloured symbols represent the different entries analysed as from the legend 
are reported in Additional file 7: Table S3. A part differences between entries, populations obtained with three years of multiplication did not significantly differ from those obtained with two years of multiplication for all genetic parameters, with the exception of $\mathrm{Na}$ observed in Syn2-GR and Syn3-GR. Finally, pairwise Fst comparisons (Table 3) ranged from 0.005 to 0.159 between populations. Population differentiation increased across locations and generations of multiplication. The highest differentiation was found between Syn2-TER and Syn3-TER.

$\mathrm{NJ}$ tree results, beside a clear differentiation between populations and hybrids, showed that Syn2-TER, Syn3TER, Syn3-GR, and partially Syn3-PG appeared to belong to four different and distinguished clusters (Additional file 8: Figure S5). The first three components of the PCoA accounted for $82.63 \%$ of genetic variation (Additional file 9: Figure S6). Populations and $\mathrm{H}$ were clearly discriminated from $\mathrm{HH}, \mathrm{HHH}$ and $\mathrm{HHHH}$. Finally, Syn3-GR, Syn2-TER and Syn3-TER were clearly differentiated from all the other populations.

\section{Discussion}

To the best of our knowledge this is the first insight into the morphological and genetic short-term evolution and local adaptation of broccoli populations developed by a EBP for sustainable agriculture.

The populations here studied could be compared to natural populations, that are mainly represented by genotypes derived from the most fit plants and that mainly evolve in relationship to environmental pressures, because the EBP applied (i.e. the choice of the most vigorous plants for reproduction) favoured plants with the largest heads and then the greatest production of seed in each environment.

Although several experiences of evolutionary breeding for autogamous species have been reported by different authors $([8,12]$ and references therein, $[33,34])$, a few EBP have been registered for allogamous species like broccoli $[23,35,36]$.

As for the comparison of populations developed in different countries, the selection pressures (those applied by different researchers by choosing three plants during multiplication of populations and those linked to different pedo-climatic conditions) did not seem to have heavily changed the morpho-phenological traits and the performances of populations in comparison with LR from which they derived. The populations showed few morphological differences probably due to their intrinsic plasticity, the initial genetic diversity of LR and the mating system of the species, factors that, combined, maintain a large variability [30]. In addition, it is possible that the most vigorous chosen plants per generation had the highest heterozygosity and different alleles were consequently maintained across generations. Similar results were also found by $[35,36]$ who evaluated the morphological changes in spinach and maize in few years of multiplication in different environments, respectively.

Only populations multiplied in TER were morphologically well distinguished from the other populations. TER is an environment that showed minimum temperatures lower than the others among December and March: these environmental factors could have negatively influenced the vegetative stage of plants and consequently the reproductive stage, since from December to March the heads appear and then proceed to maturation.

Also, the EBP here described (selection and mating of the best tree plants for two years) did not seem to have resulted in any inbreeding depression, suggesting that the genetic diversity remained high.

In spite of that, genetic data showed a differentiation among populations that morphological data did not assess. Only two years of multiplication caused a low to moderate differentiation. Worth of note is the progressive increase in differentiation values observed passing from different population generations and from a multiplication environment to another.

Of course, a longer breeding period or a different selection method than the one implemented in this study could have allowed a greater differentiation among populations, as it happens in the process of broccoli LR differentiation [31]. For example, as suggested by results of [23], in which the final versions of two maize populations showed low differentiation from the original populations, mass selection resulted less selective than a RRS implemented for a similar period [18]. In addition, in both maize mass and RSS, a long breeding program increased the genetic differentiation among original and final breeding populations [18, 37], probably as a consequence of allele fixation [18, 38]. In fact, if $2-4$ cycles of RRS slightly reduce diversity, with an allele loss up to $11 \%[20,22,39], 11-12$ cycles of RRS reduce diversity much more, with an allele loss up to $37 \%[17,40]$.

Our genetic results were similar to those found by [23] (comparing two open-pollinated maize populations undergone to stratified mass selection for 19 and 25 years) and to those found by [20] who (comparing two maize synthetic varieties after two cycles RRS) found that the genetic differentiation among versions of the same population was very low.

In this study, the short selection period and/or the low pressure breeding method resulted in the maintenance of a high intra-population genetic diversity.

Also in maize a study of molecular changes during intra- and inter- recurrent selection on one adapted and one non adapted populations suggested that natural selection acted stronger than breeding in differentiating the populations obtained in the non adapted population 
only [21]. Similarly, passing from a multiplication environment to another, we observed an increase of differentiation between the same population generations. Although in this study on broccoli environmental pressures did not strongly affected genetic diversity as in maize [21], indeed they played a role in differentiating populations.

The comparisons of populations developed in Central Italy for up to three cycles confirmed what observed comparing populations developed in different countries. The SSR data highlighted a genetic differentiation among populations that was not evident with only morphological data. With respect to populations obtained after two cycles of multiplication, one more year of multiplication determined a greater genetic differentiation among populations: genetic distance between Syn1-PG and Syn3-PG was greater than between Syn1PG and Syn2-PG. Also, the highest Fst values were those between the final versions of populations multiplied in different environments.

In addition, genetic data showed that the environment of adaptation (Perugia, the environment in which LR is grown and the original selection was carried out in order to develop the Syn1-PG) was less selective than the others. In fact, even if the genetic distance among the Syn1-PG and the derived populations was increasing along years, the increase was larger in the TER and GR environments, which are not the adaptation environments.

During an EBP the selective pressure of environments is crucial, but time is also an important factor in driving the oscillations of the allele frequencies and the subsequent adaptation of the genotypes.

\section{Conclusions}

One of the aims of this study was to assess the adaptation potential of a heterogeneous variety when multiplied in different environments. Although a longer multiplication period would be necessary to have a final confirmation, the obtained data show that a high genetic diversity is maintained all over the tested multiplication environments and in spite of their pedological and climatic differences in at least three years. This diversity can then continue to evolve in response to different selection pressures in each environment in the future, as it has always happened with any introduction of variable materials in different environments in the past.

Few years of multiplication in different environments resulted in differentiated populations which, nonetheless, preserved the original genetic diversity and productivity level and appear able to evolve in relationship to different environments.

As such the EBP here described also appears to be a good method to develop broccoli materials (populations) for sustainable agricultural systems, those systems where the use of external input (pesticides, irrigation, fertilisers that help a crop facing adversities) is limited or absent.

In sustainable agricultural systems, protection from biotic and abiotic stress (which are variable from year to year and from a situation to another) should rely on the diverse response of the single different genotypes at a certain moment and, consequently, on the ability of the crop, as a whole, to change its composition across time, making the crop community diverse and resistant/tolerant across time and situation. This changing ability is also important because sustainable systems often have very specific characteristics in term of soil fertility, type of occurring biotic and abiotic stress, agronomic and protection techniques applied by farmers (also in relation to their own skills and preferences). In most cases none is similar to another. Finally, it is also important because we are living in a period of rapid and unpredictable climatic changes, with the connected changes of biological forms negatively affecting crops.

For all these reasons, in sustainable agriculture populations like those developed in this study, which are able to evolve across time and locations, appear to be much more suitable materials than hybrids and greater efforts than presently carried out should be applied to develop and diffuse them. Of course, where external inputs can counteract biotic and abiotic constrains and the cultivation environment is uniform, hybrid varieties can be the most useful materials.

\section{Materials and methods}

\section{Plant breeding procedure}

Aiming to develop materials suitable for organic agriculture (i.e. possessing the adaptation and the intrinsic diversity needed to suit a particular environment) we specifically focused our work on a landrace (LR) instead of on other materials.

We chose a sprouting broccoli LR from Umbria (Central Italy) that is named "Zolfino", highly appreciated on the local market and generally grown under low-input conditions. The LR is characterised by late flowering and maturation: requiring low winter temperatures for flower induction, it is harvested in a period spanning from beginning of March to mid-April. Initially the main head, then the lateral buds are harvested in the period.

The initial material of LR was obtained by a farmer family which cultivated it since generations. After the farmer abandoned his own population, this Department (DSA3) continued its cultivation by yearly reproducing the seed and applying the selection procedures of the mother plants (MP) suggested by the farmer: the most vigorous 2 or $3 \mathrm{MP}$, among the 25 usually grown, are chosen and intercrossed, while the field is cleared from other $B$. oleracea plants, since all the species varieties 


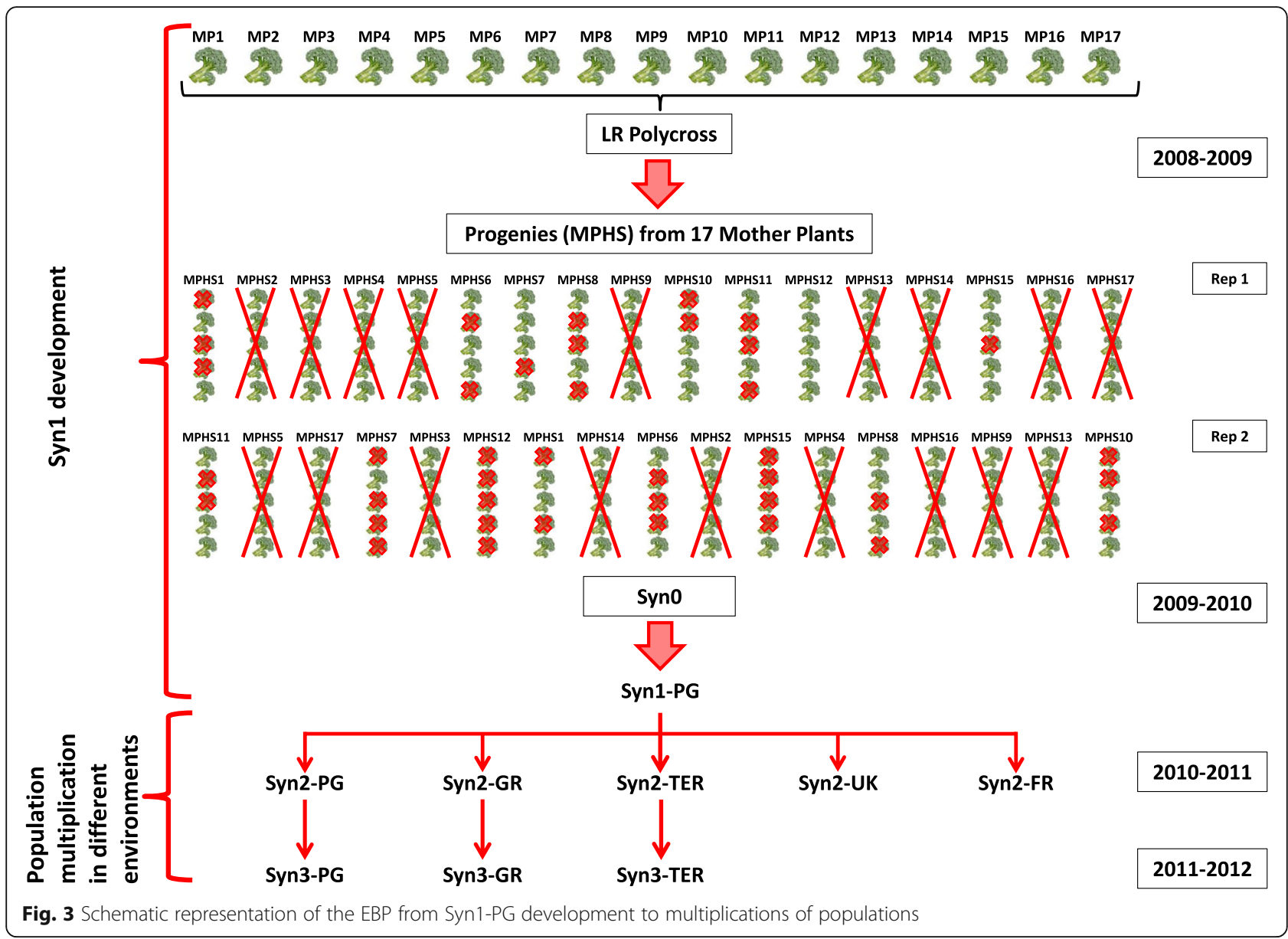

are interfertile. It should be noted that this procedure is common across Europe for farmers reproducing their $B$. oleracea LR (V. Negri personal communication).

Starting a breeding program to develop an initial synthetic in 2009, we asked the farmer to choose $17 \mathrm{MP}$ among the 25 grown instead of the usual number (Fig. 3). The following year, 10 plants for each of the $17 \mathrm{MP}$ half sib progenies (MPHS) were grown in a trial (5 plants for each MPHS in each of 2 replicates, for a total of 170 plants). Such a high number of plants was adopted in order to maintain the initial LR diversity as much as possible. Among them, the farmer was asked to select, according to his personal opinion, the best 8 MPHS and then, within each of them, the best 5 plants. Accordingly, a synthetic variety (Syn0) made of 40 plants from the initial 8 MPHS, that mirrors the original LR, was obtained.

The multiplication of Syn0 produced a Syn1-PG (2009-2010), the initial (foundation) material of this study.

To start the EBP the Syn1-PG seed was then multiplied in isolation in different areas of Central Italy, in France and in United Kingdom as follows (Fig. 3): i) for two consecutive years at DSA3 (Perugia, Umbria Region) in the same area of its origin giving rise to two populations named Syn2-PG (2010-2011) and Syn3-PG (2011-2012), respectively;

ii) for two consecutive years in two other areas of Central Italy with different pedo-climatic conditions from Perugia: Grosseto (Tuscany) and Terminillo (Lazio), giving the populations named Syn2-GR, Syn3-GR and Syn2-TER and Syn3-TER, respectively;

iii) for one year only (2010-2011) in United Kingdom giving a population named Syn2-UK;

iv) for one year only (2010-2011) in France giving a population named Syn2-FR.

Each multiplication environment (GR, TER, UK and FR) is different from PG for several pedo-climatic traits (Additional file 1: Figure S1, [27]). Such different environmental conditions were purposely chosen to assess the degree of restriction in genetic diversity due to selective pressure.

As it is usual for this type of LR, in all sites the seeds obtained from each multiplication cycle was sowed in 
pots at the beginning of July and the plantlets were transplanted in the experimental field at the beginning of September. The seed was harvested in June in Italy, and about a month later in France and United Kingdom.

In each multiplication cycle and in each environment only the three most vigorous plants (in agreement with farmer indications) were intercrossed in order to obtain seed. The inflorescences of the other plants were cut before flowering in order to evaluate agronomic traits of the commercial heads.

Each year, the obtained seed was sent to DSA3 in order to store it in its Genebank (FAO code ITA363) for the successive analyses (see below).

For each environment of multiplication and for the environment of final agronomic trial, climatic data, i.e. average daily temperature, average of maximum daily temperatures, average of minimum daily temperatures $\left({ }^{\circ} \mathrm{C}\right)$ and total rainfall precipitations $(\mathrm{mm})$ (obtained from near-by weather stations), were recorded from sowing to harvest (Additional file 1: Figure S1).

\section{Evaluated plant material}

The materials obtained from multiplication in different environments was used to assess the occurrence morphophenological and genetic changes.

Firstly, particularly to understand the effects of multiplication in different countries, we assessed the diversity of genotypes belonging to 11 entries of broccoli: seven populations and four hybrids used as controls. Specifically: the Umbrian LR, the Syn1-PG, its five two year multiplications, Syn2-PG, Syn2-GR, Syn2-TER, Syn2-UK and Syn2-FR, and the hybrids Santee (Elsomseed), Ironman (Monsanto), Belstar (Bejo Seeds) and Natura Vallata (Cooperativa Agricola Cesenate), named $\mathrm{H}, \mathrm{HH}$, $\mathrm{HHH}$ and $\mathrm{HHHH}$, respectively.
Secondly, we assessed other three populations obtained in Central Italy with a further multiplication cycle (Syn3-PG, Syn3-TER and Syn3-GR) in order to obtain information about further evolutionary processes eventually occurred.

\section{Assessment of morpho-phenological changes occurred with multiplications}

In order to assess eventual morpho-phenological changes, all the obtained multiplications were evaluated in the same environment.

Seeds from the 14 broccoli entries were sown in pots at the beginning of July and the obtained plantlets were transplanted in a DSA3 experimental field in Perugia (Umbria, Italy) at the beginning of September. A total of 448 individual plants were evaluated. Plants were arranged by using a randomised block design with four replications. In each plot, eight plants of each entry were grown, for a total of 32 plants evaluated per entry. Spacing among plants was set at $1 \times 1 \mathrm{~m}$ because the plants are very vigorous and this spacing is generally used by farmers growing the "Zolfino" LR (Additional file 2: Figure S2). The management practices applied to the agronomical trial were similar to those used in organic agriculture conditions in the area. Fertilization was ensured by pre-implant livestock manuring, by using $1 \mathrm{t}$ $\mathrm{ha}^{-1}$ of the commercial product NUTEX LETAME (Agroqualità, $3 \% \mathrm{~N}$ and $3 \% \mathrm{P}_{2} \mathrm{O}_{5}$ content) that was incorporated by using a rotary cultivator. As above, this is the fertilization level usually applied by farmers. Weed control was always performed by hand-weeding and no chemical control of pathogens and insects was applied. Broccoli were irrigated immediately after transplanting and during the following month, aiming at fully restoring crop evapotranspiration.

Table 4 Morphological and phenological traits, their description and codes

\begin{tabular}{|c|c|c|}
\hline Trait & Description of method of detection & Code \\
\hline Days to heading & Number of days from sowing to head emission (dd) & $\mathrm{DH}$ \\
\hline Days to maturity & Number of days from sowing to maturity of the main head (dd) & $D M$ \\
\hline Head number & Number of secondary heads at maturity of the main head ( $n$ ) & $H N$ \\
\hline Yield & Fresh weight of the main head $(\mathrm{g})$ & $Y L D$ \\
\hline Mean Yield & Average weight of heads $(T-Y L D /(H N+1))$ & $M-Y L D$ \\
\hline Total-Yield & Fresh weight of the total heads per plant $(\mathrm{g})$ & $T-Y L D$ \\
\hline Head height & Longitudinal dimension of the main head $(\mathrm{cm})$ & $\mathrm{HeH}$ \\
\hline Head width & Width of the main head (mm) & HeW \\
\hline Stem width & Width of the main head stem (mm) & SW \\
\hline Plant height & Height of the plant (cm) & $\mathrm{PH}$ \\
\hline Plant diameter & Diameter of the plant $(\mathrm{cm})$ & $P D$ \\
\hline Vigour & Plant vigour (Score from $\min =0$ to $\max =9$ ) & V \\
\hline
\end{tabular}


Twelve morpho-phenological traits were recorded for each plant on all entries (Table 4).

To determine the significance of the sources of variation, the recorded data were processed by analysis of variance (ANOVA) using a linear model, where an individual trait value $\mathrm{T}_{\mathrm{ij}}$ of the levels $\mathrm{i}$ of the effect "Genotype" (G), and $j$ of the effect "Block" (B), is: $T_{i j}=m+$ $G_{i}+B_{j}+e_{i j}$, where $m$ is the grand mean and $e_{i j}$ is the experimental error, and means were separated using the Tukey Honest Significant Difference (HSD), as implemented in the HSD.test () function of the "agricolae" package in $\mathrm{R}[41,42]$.

In order to study the correlation pattern of the considered morpho-phenological traits and the differences among entries, a principal components analysis (PCA) was performed by using the function $\mathrm{PCA}()$ of the "FactoMineR" package [43]. PCA is a factor analytic technique that is used for the ordination of observations in a reduced rank space. It is used to visualise the weight of variables in determining entry ordination (as shown by vector lengths, by angles between vectors and by the reciprocal positioning of variable vectors and entry symbols). As a preliminary step before performing a PCA on the complete dataset, the missing values were imputed with the Principal Components Analysis model by the function imputePCA() of the "missMDA" package [44].

\section{Assessment of genetic changes occurred with multiplications \\ Genomic DNA extraction}

Fifty $\mathrm{mg}$ of fresh leaf tissue were collected from each of the 448 plants (32 plants for each of 14 entries) and high quality DNA was isolated using the DNeasy 96 Plant Kit (Quiagen). DNA quality and concentration were checked by spectrophotometry using NanoDrop 2000 (Thermo Scientific) and 1.0\% (w/v) agarose gel separation.

\section{Microsatellite analysis}

Broccoli individuals were genotyped using 17 putative neutral microsatellite markers (SSR) [45-47] and five microsatellites related to genes involved in flowering control and cold stress response (EST-SSR) [48] (Additional file 3: Table S1). According to their position on B. oleracea chromosomes, the selected markers are not in linkage (i.e. for each chromosome, the two selected markers are located on the two different arms). All the DNA amplifications were carried out as described in [49]. Obtained amplicons were separated in a 3130xl capillary sequencer (Applied Biosystems), sized according to the internal size standard GeneScanTM23 500 LIZ $^{\circ}$ (Applied Biosystems), visualised and scored using the GENEMAPPER software (Applied Biosystems).

For each SSR marker the number of alleles and allele size range were recorded. The number of successfully analysed $(N)$ and observed $(\mathrm{Na})$ genotypes, the effective $(\mathrm{Ne})$ number of observed alleles, observed $(\mathrm{Ho})$, as well as the expected $(\mathrm{He})$ heterozygosity and the Fixation Index $(F)$, were worked out by entry (i.e. LR, Syn1-PG, its derived populations and hybrid controls) with the use of GENALEX software [50]. For each parameter, the average values were compared by using the Tukey Honest Significant Difference (HSD) as implemented in the HSD.test() function of the "agricolae" package in R [41, 42].

In order to assess the components of molecular variation, an Analysis of Molecular Variance (AMOVA) was worked out following the method of [51] as implemented in GENALEX software [50].

Pairwise comparison Fst values and two Genetic Distance (GD) matrices between individuals following the formula of [52] were calculated using GENALEX software [50]. Two GD-based Neighbour Joining (NJ) trees were drawn using the on-line software iTOL [53]. To better understand the genetic relationship among entries, two Principal Coordinate Analysis (PCoA) were also worked out by using the same distance matrices and drawn by "scatterplot3d" package in R $[42,54]$.

\section{Supplementary information}

Supplementary information accompanies this paper at https://doi.org/10. 1186/s12863-020-00846-2.

Additional file 1: Figure $\mathbf{S 1}$. Monthly precipitation $(\mathrm{mm})$ and mean of minimum, maximum and average temperature $\left({ }^{\circ} \mathrm{C}\right)$. Data registered during the multiplication seasons in Perugia in 2009/2010 (PG 2009/ 2010), in Central Italy (Perugia, Grosseto e Terminillo) in 2010/2011 and 2011/2012 (PG 2010/2011, PG 2011/2012, GR 2010/2011, GR 2011/2012, TER 2010/2011 and TER 2011/2012), in United Kingdom in 2010/2011 (UK 2010/2011) and in France in 2010/2011 (FR 2010/2011), and during the final agronomic trial carried out in Perugia (PG 2013/2014). The bar chart refers to monthly precipitation, lines with squares, diamonds and circles refer to maximum, average and minimum temperature, respectively.

Additional file 2: Figure S2. Final agronomic trial carried out in the DSA3 experimental field in Perugia (Umbria, Italy). Broccoli multiplications carried out across Europe and in Central Italy were grown in the DSA3 experimental field in Perugia. The populations tested were: LR, Syn1-PG, Syn2-PG, Syn3-PG, Syn2-GR, Syn3-GR, Syn2-TER, Syn3-TER, Syn2-UK, Syn2FR. $\mathrm{H}, \mathrm{HH}, \mathrm{HHH}$ and $\mathrm{HHHH}$ are the hybrid varieties used as controls.

Additional file 3: Table S1. SSR markers used for analyze genetic diversity of broccoli original LR, Syn1-PG, its derived populations and hybrid controls. Bibliographic reference codes, genebank entry, primer sequences, repeated motif, linkage group (LG), and band range (in base pairs) relative to the 22 microsatellites used ('Love et al. 2004; ${ }^{2}$ Li et al. 2011; ${ }^{3}$ Cheng at al. 2009; ${ }^{4}$ Aksoy et al. 2013).

Additional file 4: Figure S3. Neighbour-joining tree of genetic distances of the entries (two years of multiplication). B. oleracea var. italica original LR, Syn 1-PG, its derived population by two years of multiplication across Europe and hybrid controls are coded with abbreviations and coloured with different colours as follows: LR-black, Syn1-PG-red, Syn2-PG-yellow, Syn2-GR-purple, Syn2-TER-dark green, Syn2-UK-blue, Syn2-FR-orange, $\mathrm{H}$-violet, $\mathrm{HH}$-brown, $\mathrm{HHH}$-pink, $\mathrm{HHHH}$-saddlebrown. Each individual of each entry are code whit a different number.

Additional file 5: Table S2. Average values and standard deviations of morpho-phenological traits for the entries (three years of multiplication). B. oleracea var. italica original LR, Syn1-PG, its derived populations by three years of multiplication in Central Italy and hybrid controls. Averages 
followed by the same letters are not significantly different at $P<0.05$ (Tukey HSD).

Additional file 6: Figure S4. PCA based on morpho-phenological traits recorded for each entries (three years of multiplication). B. oleracea var. italica original LR, Syn1-PG, its derived populations by three years of multiplication in Central Italy and hybrid controls. Coloured symbols represent the different entries analysed as from the legend, grey dotted arrow represent the morpho-phenological traits coded as from Table 4.

Additional file 7: Table S3. Averages and standard errors relative to the main genetic parameters calculated by entry (three years of multiplication). Number of successfully analysed genotypes $(N)$, observed $(\mathrm{Na})$, and effective alleles $(\mathrm{Ne})$, observed heterozygosity $(\mathrm{Ho})$, expected heterozygosity $(\mathrm{He})$, and Fixation Index $(F)$ worked out for original LR, Syn1-PG, its derived populations by three years of multiplication in Central Italy and hybrid controls on the basis of data recorded overall for the 22 markers used.

Additional file 8: Figure S5. Neighbour-joining tree of genetic distances of the entries (three years of multiplication). B. oleracea var. italica original $L R$, Syn 1-PG, its derived populations by three years of multiplication in Central Italy and hybrid controls are coded with abbreviations and coloured with different colours as follows: LR-black, Syn1-PG-red, Syn2-PG-yellow, Syn3-PG-light green, Syn2-GR-purple, Syn3-GR-grey, Syn2-TER-dark green, Syn3-TER-light blue, H-violet, HH-brown, HHH-pink, HHHH-saddlebrown. Each individual of each entry are code whit a different number.

Additional file 9: Figure S6. PCoA based on average genetic distance of the entries (three years of multiplication). B. oleracea var. italica original LR, Syn 1-PG, its derived populations by three years of multiplication in Central Italy and hybrid controls. Coloured symbols represent the different entries analysed as from the legend.

\section{Abbreviations}

DSA: Dipartimento di Scienze Agrarie, Alimentari e Ambientali; EBP: Evolutionary Breeding Program; CCP: Composite Cross Populations; RRS: Reciprocal Recurrent Selection; SSR: Simple Sequence Repeats; RFLP: Restriction Fragment Length Polymorphism; SNP: Single Nucleotide Polymorphism; LR: Landrace; MP: Mother Plant; MPHS: Mother Plant Half Sib; Syn: synthetic variety; PG: Perugia Environment; GR: Grosseto Environment; TER: Terminillo Environment; UK: United Kingdom Environment; FR: France Environment; H: Hybrid variety; HH: Hybrid variety; HHH: Hybrid variety; HHHH: Hybrid variety; DH: Days to heading; DM: Days to maturity; HN: Head number; YLD: Yield; M-YLD: Mean Yield; T-YLD: Total-Yield; HeH: Head height: HeW: Head width; SW: Stem width; PH: Plant height; PD: Plant diameter; V: Vigour; PCA: Principal components analysis; PCoA: Principal Coordinate Analysis; N: Number of successfully analysed genotypes; Na: Number of successfully genotypes; Ne: Effective number of observed alleles; Ho: Observed heterozygosity; He: Expected heterozygosity; F: Fixation Index; GD: Genetic distance; NJ: Neighbour Joining

\section{Acknowledgments}

Thanks are due to the personnel of the Centro Appenninico del Terminillo of Università degli Studi di Perugia and in particular Dr. Valeriano Valeriani, of The Organic Research Centre (ORC) and of Istitute Technique de I'Agriculture Biologique (ITAB) for multiplying of populations in Central Italy, United Kingdom and France, respectively.

\section{Authors' contributions}

VN conceived the research; SC performed experiments and analyzed the data; SC and VN wrote the manuscript. All authors read and approved the final manuscript.

\section{Funding}

The research leading to these results was funded by the European Community's Seventh Framework Programme (FP7/2007-2013) under the grant agreement $n^{\circ} 245058$ SOLIBAM (Strategies for Organic and Low-Input Integrated Breeding and Management).

The funding body played no role in the design of the study and collection, analysis, and interpretation of data and in writing the manuscript.

\section{Availability of data and materials}

The datasets used and/or analyzed during the current study are available from the corresponding author on reasonable request.

Ethics approval and consent to participate

Not applicable.

\section{Consent for publication}

Not applicable.

\section{Competing interests}

The authors declare that they have no competing interests.

Received: 10 July 2019 Accepted: 24 March 2020

Published online: 07 May 2020

\section{References}

1. FAOSTAT. FAOSTAT crops production data. 2018. http://www.fao.org/ faostat/en/\#data/QC

2. SINAB. Superfici biologiche per anno, prodotto e regione (ettari) - Cavolfiore e broccoli. 2018. http://www.sinab.it/content/superfici.

3. Hammer K, Gladis T, Laghetti G, Pignone D. The wild and the grownremarks on Brassica. Int J AgriSci. 2013;3:453-80 http://www.cabdirect.org/ abstracts/20133227404.html. Accessed 13 May 2014.

4. Lammerts van Bueren ET, Struik PC, Jacobsen E. Ecological concepts in organic farming and their consequences for an organic crop ideotype. Neth J Agric Sci. 2002;50:1-26. https://doi.org/10.1016/S1573-5214(02)80001-X.

5. Torricelli R, Ciancaleoni S, Negri V. Performance and stability of homogeneous and heterogeneous broccoli (Brassica oleracea L. var. italica Plenck) varieties in organic and low-input conditions. Euphytica. 2014;199.

6. Lammerts van Bueren ET, Jones SS, Tamm L, Murphy KM, Myers JR, Leifert C, et al. The need to breed crop varieties suitable for organic farming, using wheat, tomato and broccoli as examples: A review. NJAS - Wageningen J Life Sci. 2011;58:193-205. https://doi.org/10.1016/j.njas.2010.04.001.

7. Ceccarelli S. Efficiency of plant breeding. Crop Sci. 2015;55:87. https://doi. org/10.2135/cropsci2014.02.0158.

8. Dawson J, Goldringer I. Breeding for genetically diverse populations: variety mixtures and evolutionary populations. In: Lammerts Van Bueren ET, Myers J, editors. Chichester: Wiley-Blackwell; 2012. p. 77-98. https://doi.org/10. 1002/9781119945932.ch5.

9. Döring TF, Annicchiarico P, Clarke S, Haigh Z, Jones HE, Pearce $\mathrm{H}$, et al. Comparative analysis of performance and stability among composite cross populations, variety mixtures and pure lines of winter wheat in organic and conventional cropping systems. Field Crop Res. 2015;183:235-45. https://doi. org/10.1016/j.fcr.2015.08.009.

10. Finckh M, Brumlop S, Goldringer I, Steffan P, Wolfe MS. Maintenance of diversity in naturally evolving composite cross wheat populations in Europe. Collected papers of the 1st IFOAM conference on organic animal and plant breeding. Tholey-Theley. 2009. p 145-52.

11. Murphy K, Lammer D, Lyon S, Carter B, Jones SS. Breeding for organic and low-input farming systems: an evolutionary-participatory breeding method for inbred cereal grains. Renewable Agric Food Syst. 2005;20:48-55. https:// doi.org/10.1079/RAF200486.

12. Phillips SL, Wolfe MS. Evolutionary plant breeding for low input systems. J Agric Sci. 2005;143:245-54.

13. Raggi L, Ceccarelli S, Negri V. Evolution of a barley composite-derived population: an insight gained buy molecular markers. J Agric Sci. 2015:1-7.

14. Goldringer I, Prouin C, Rousset M, Galic N, Bonnin I. Rapid differentiation of experimental populations of wheat for heading time in response to local climatic conditions. Ann Bot. 2006;98:805-17.

15. Kutka F, Smith M. How many parents give the highest yield in predicted synthetic and composite populations of maize? Crop Sci. 2007:47:1905-13.

16. Koutis K. Multienvironmental evaluation of wheat landraces by GGE Biplot analysis for organic breeding. Agric Sci. 2012;3:66-74. https://doi.org/10. 4236/as.2012.31009.

17. Labate JA, Lamkey KR, Lee M, Woodman WL. Temporal changes in allele frequencies in two reciprocally selected maize populations. Theor Appl Genet. 1999:99:1166-78.

18. Labate JA, Lamkey R, Lee M, Woodman WL. Molecular genetic diversity after reciprocal recurrent selection in BSSS and BSCBI maize populations. Crop Sci. 1997;37:416-23. 
19. Rossini Pinto L, Carneiro Vieira ML, Lopes De Souza C, Pereira De Souza A. Genetic-diversity assessed by microsatellites in tropical maize populations submitted to a high-intensity reciprocal recurrent selection. Euphytica. 2003; 134:277-86.

20. Ordas B, Malvar RA, Díaz R, Butron A. Molecular changes in two maize (Zea mays $L$.) synthetics after reciprocal selection with two alternative methods. Mol Breed. 2015;35(4):111.

21. Peña-Asin J, Álvarez A, Ordas B. Molecular changes during intra and inter recurrent selection of two populations of maize: one adapted and one non adapted to the selection environment. Euphytica. 2013;193:359-67.

22. Kolawole AO, Menkir A, Gedil M, Blay E, Ofori K, Kling JG. Genetic divergence in two tropical maize composites after four cycles of reciprocal recurrent selection. Plant Breed. 2017;136:41-9.

23. Alves ML, Belo M, Carbas B, Brites C, Paulo M, Mendes-Moreira P, et al. Long-term on-farm participatory maize breeding by stratified mass selection retains molecular diversity while improving agronomic performance. Evol Appl. 2018;11:254-70.

24. Enjalbert J, Goldringer I, Paillard S, Brabant P. Molecular markers to study genetic drift and selection in wheat populations. Comptes Rendus Biologies. 1999;50:283-90.

25. Enjalbert J, Boeuf C, Belcram H, Leroy P. Use of multiparental inbred populations to determine allelic relationships of molecular markers. Plant Breed. 1999;118:88-90.

26. Rousselle Y, Thomas M, Galic N, Bonnin I, Goldringer I. Inbreeding depression and low between-population heterosis in recently diverged experimental populations of a selfing species. Heredity. 2011;106:289-99. https://doi.org/10.1038/hdy.2010.72.

27. Ciancaleoni S, Onofri A, Torricelli R, Negri V. Broccoli yield response to environmental factors in sustainable agriculture. Eur J Agron. 2016;72:1-9.

28. Sahamishirazi S, Moehring J, Zikeli S, Fleck M, Claupein W, Graeffhoenninger S. Agronomic performance of new open pollinated experimental lines of broccoli (Brassica oleracea $\mathrm{L}$. var. italica) evaluated under organic farming. PLoS One 2018;13:1-13. https://doi.org/https://doi. org/10.1371/journal.pone.0196775.

29. Renaud ENC, Lammerts Van Bueren ET, Myers JR, Paulo MJ, Van Eeuwijk FA, Zhu N, et al. Variation in broccoli cultivar phytochemical content under organic and conventional management systems: implications in breeding for nutrition. PLoS One. 2014;9(7).

30. Ciancaleoni S, Raggi L, Negri V. Genetic outcomes from a farmer-assisted landrace selection programme to develop a synthetic variety of broccoli. Plant Genetic Resources: Characterisation and Utilisation, vol. 12; 2014.

31. Branca F, Chiarenza GL, Cavallaro C, Honghui G, Zhenqing Z, Tribulato A. Diversity Sicilian broccoli (Brassica oleracea var. italica) and cauliflower (Brassica oleracea var. botrytis) landraces and their distinctive biomorphological, antioxidant, and genetic traits. Genet Resour Crop Evol 2018; 65:485-502. https://doi.org/https://doi.org/10.1007/s10722-017-0547-8.

32. Li Z, Mei $Y$, Liu $Y$, Fang Z, Yang L, Zhuang $M$, Zhang $Y$, Lv H. The evolution of genetic diversity of broccoli cultivars in China since 1980. Sci Hortic 2019;250:69-80. https://doi.org/https://doi.org/10.1016/j.scienta. 2019.02.034

33. Raggi L, Ciancaleoni S, Torricelli R, Terzi V, Ceccarelli S, Negri V. Evolutionary breeding for sustainable agriculture: selection and multi-environmental evaluation of barley populations and lines. Field Crop Res. 2017:204:76-88.

34. Suneson C. An evolutionary plant breeding method. Agron J. 1956;48:188-91.

35. Serpolay E, Schermann N, Dawson J, Lammerts van Bueren ET, Goldringer I, Chable V. Phenotypic changes in different spinach varieties grown and selected under organic conditions. Sustainability. 2011;3:1616-36.

36. Serpolay-Besson E, Giuliano S, Schermann N, Chable V. Evaluation of evolution and diversity of maize open-pollinated varieties cultivated under contrasted environmental and farmers' selection pressures: a phenotypical approach. Open J Genet. 2014;4:125-45.

37. Zou CY, Li LJ, Yang KC, Pan GT, Rong TZ. Effects of mass selection on maize synthetic populations. Acta Agron Sin. 2010;36:76-84. https://doi.org/10. 1016/S1875-2780(09)60028-6.

38. Hagdorn S, Lamkey KR, Frisch M, Guimarães PEO, Melchinger AE. Molecular genetic diversity among progenitors and derived elite lines of BSSS and BSCB1 maize populations. Crop Sci. 2003:43:474-82.

39. Butrón A, Tarrío R, Revilla P, Ordás A, Malvar RA. Molecular changes in the maize composite EPS12 during selection for resistance to pink stem borer. Theor Appl Genet. 2005;110:1044-51.
40. Solomon KF, Martin I, Zeppa A. Temporal genetic structure patterns in tropical maize populations under reciprocal recurrent selection. Euphytica. 2010;176:239-49.

41. De Mendiburu F. Una herramienta de analisis estadistico para la investigacion agricola. PhD Thesis. Universidad Nacional Agraria La Molina (UNI-PERU); 2009.

42. R Development Core Team. R: a language and environment for statistical computing. Vienna. Retrieved from http://www.R-project.org: R Foundation for Statistical Computing; 2013.

43. Husson F, Josse J, Le S, Mazet J. FactoMineR, multivariate exploratory data analysis and data mining with R. R package version 12 Retrieved from http,//CRANR project.org/package = FactoMineR. 2013

44. Josse J, Husson F. missMDA: a package for handling missing values in multivariate data analysis. J Stat Softw. 2016;70:1-31.

45. Lowe A, Moule C, Trick M, Edwards KJ. Efficient large-scale development of microsatellites for marker and mapping applications in Brassica crop species. Theor Appl Genet. 2004;108:1103-12. https://doi.org/10.1007/ s00122-003-1522-7.

46. Cheng X, Xu J, Xia S, Gu J, Yang Y, Fu J, et al. Development and genetic mapping of microsatellite markers from genome survey sequences in Brassica napus. Theor Appl Genet. 2009;118:1121-31. https://doi.org/10. 1007/s00122-009-0967-8.

47. Li H, Chen X, Yang Y, Xu J, Gu J, Fu J, et al. Development and genetic mapping of microsatellite markers from whole genome shotgun sequences in Brassica oleracea. Mol Breed. 2011;28:585-96. https://doi.org/10.1007/ s11032-010-9509-y.

48. Aksoy S, Almeida-val VMF, Azevedo VCR, Baucom R, Bazaga P, Beheregaray LB, et al. Permanent Genetic Resources added to Molecular Ecology Resources Database 1 October 2012-30 November 2012. Mol Ecol Resour Note. 2013;13:341-3

49. Ciancaleoni S, Chiarenza GL, Raggi L, Branca F, Negri V. Diversity characterisation of broccoli (Brassica oleracea L. var. italica Plenck) landraces for their on-farm (in situ) safeguard and use in breeding programs. Genet Resour Crop Evol. 2013;61:451-64. https://doi.org/10.1007/s10722-013-0049-2.

50. Peakall R, Smouse PE. Genalex 6: genetic analysis in excel. Population genetic software for teaching and research. Mol Ecol Notes. 2006;6:288-95. https://doi.org/10.1111/j.1471-8286.2005.01155.x.

51. Michalakis $Y$, Excoffier L. A generic estimation of population subdivision using distances between alleles with special reference for microsatellite loci. Genetics. 1996;142:1061-4.

52. Nei M. Estimation of average heterozygosity and genetic distance from a small number of individuals. Genetics. 1978;89:583-90.

53. Letunic I, Bork P. Interactive tree of life (iTOL) v3: an online tool for the display and annotation of phylogenetic and other trees. Nucleic Acids Res. 2016;44:W242-5

54. Ligges U, Machle M. Scatterplot3d - an R package for visualizing multivariate data. J Stat Softw. 2003;8:1-20.

\section{Publisher's Note}

Springer Nature remains neutral with regard to jurisdictional claims in published maps and institutional affiliations.

Ready to submit your research? Choose BMC and benefit from:

- fast, convenient online submission

- thorough peer review by experienced researchers in your field

- rapid publication on acceptance

- support for research data, including large and complex data types

- gold Open Access which fosters wider collaboration and increased citations

- maximum visibility for your research: over $100 \mathrm{M}$ website views per year

At $\mathrm{BMC}$, research is always in progress.

Learn more biomedcentral.com/submission 